\title{
Los i-memes como medio de participación ciudadana en las relaciones diplomáticas a partir de un estudio de caso: \#PERDÓNESPAÑA
}

\author{
Laura Romero de Vara $^{1}$
}

Enviado: 9 marzo 2020 / Aceptado: 17 abril 2020

Resumen. El presente artículo demuestra cómo los i-memes son utilizados por los usuarios para transmitir opiniones y posiciones en temas de diplomacia. A partir del estudio de caso de la controversia suscitada entre México y España, después de las declaraciones en redes sociales del actual presidente mexicano, en las que urgía al rey de España a pedir perdón, por los daños causados durante la conquista de México, se analizan los memes encontrados en diversas plataformas como: Google, Twitter, Facebook y Whatsapp. Se concluye que los memes de internet se han convertido en un elemento fundamental de los procesos comunicativos del siglo XXI, siendo su estudio esencial para entender cómo funciona la opinión pública en la sociedad en red.

Palabras clave: memes; cultura; comunicación; opinión pública; diplomacia digital.

\section{[en] The $i$-memes as a means of citizen participation in diplomatic relations based on a case study: \#FORGIVESPAIN}

\begin{abstract}
This article shows how the i-memes are utilized by the users in order to transmit their thinking and position in diplomacy topics. From the case study of the controversy between Mexico and Spain, after the statements on social networks of the current Mexican president, in which he urged the King of Spain to apologize, for the damages caused during the conquest of Mexico, analyzing the memes found on platforms such as: Google, Twitter, Facebook and WhatsApp. It is concluded, that internet memes have become a fundamental element of the communication process in 21 st century and therefore, its study us essential in order to understand how the public opinion works in the network society.

Keywords: memes; culture; communication; public opinion; digital diplomacy.
\end{abstract}

Sumario: 1. Introducción: una breve inmersión en el mundo de los memes. 2. Objetivos y Metodología. 3. Caso de estudio: \#PerdónEspaña. 4. Análisis de los memes. 5. Conclusiones. 6. Referencias bibliográficas.

Cómo citar: Romero de Vara, L. (2020). Los i-memes como medio de participación ciudadana en las relaciones diplomáticas a partir de un estudio de caso: \#PERDÓNESPAÑA, en CIC. Cuadernos de Información y Comunicación 25, 201-223. 


\section{Introducción: una breve inmersión en el mundo de los memes}

La sociedad hiperconectada del siglo XXI ha encontrado una forma rápida, concisa, graciosa y creativa de expresar sus críticas hacia el mundo, a través de estas pequeñas unidades informativas de saber popular, conocidas comúnmente como "memes". Pero ¿qué son los memes?, ¿cuándo y por qué surgen?, ¿cómo se transmiten?, ¿por qué se viralizan?, ¿cuánto tiempo sobreviven y de que depende? En esta sección se tratarán de resolver estas incógnitas relacionadas con los memes.

¿Quién no ha visto, recibido, compartido, comentado o reído con algún meme? Seguramente, la mayoría de los lectores, identifican claramente alguna imagen con texto añadido de Mia Talerico, mejor conocida como la niña "o sea qué pedo", Laina Morris "la novia psicópata" o Sammy Griner "el niño exitoso".

Se identifica a Richard Dawkins como el pionero en utilizar el término "memética" en el capítulo XI de su libro "El gen egoísta", lugar en donde plasma la idea de que al igual que los genes, como mínima división de los seres vivos, los memes son los entes más pequeños de información que se reproducen y se difunden entre los individuos, con el fin de compartir conocimiento e ideas (Dawkins, 1989: 270).

La teoría de la memética de Dawkins englobaba todo lo que se refiere a la "transmisión cultural" (Dawkins, 1989: 266). Es decir, desde el conocimiento de una canción popular, ritos, costumbres, hasta la propagación de una teoría científica.

Para efectos del presente trabajo de investigación, únicamente se tomarán en cuenta los "memes" que se comparten en Internet. Generalmente en las redes sociales, y que constituyen una forma de expresión, de respuesta o posicionamiento ante un suceso o acontecimiento alrededor del mundo.

Los memes de internet o "i-memes" pueden ser definidos como unidades de información plasmadas en cualquier formato digital (imágenes macro, videos, texto, entre otros) que se utilizan para describir situaciones, compartir ideas y opiniones, realizar críticas hacia algún suceso y que, por el tono humorístico y sarcástico que utilizan, tienden a "viralizarse" en red, es decir, se comparten copias fieles del contenido, se interactúa e inclusive, se realizan modificaciones del contenido original.

De acuerdo con Dassaev García (2014), dentro del estudio de los memes, se encuentran las imágenes macro, las cuales, no son otra cosa que una fotografía, dibujo o ilustración con un texto sobrepuesto. Este último, suele ser un mensaje ingenioso, irónico o humorístico, comúnmente utilizado para enfatizar. Asimismo, es fundamental que el mensaje sea breve, de tal manera que las palabras que acompañan las imágenes sean comprendidas inmediatamente (Alarcón, 2017:126)

Todos estos memes, tal y como ya lo anunciaba Dawkins, "aportan una respuesta superficial plausible a problemas profundos e inquietantes de la existencia" (Dawkins, 1989: 271) y el mecanismo de selección "favorece los memes que explotan su medio cultural para su propia ventaja" (ibid.: 280); es decir, las llamadas "tradiciones", las "identidades", o sencillamente, los lugares comunes y las costumbres cotidianas, sean las que sean" (Eva, 2013: 3).

Los memes que se difunden en internet son creados, en la mayoría de las ocasiones, por los propios usuarios, enfatizando su capacidad de inventiva y la facultad de participación de los ciudadanos obtenida, gracias al acceso y uso generalizado del internet y las TICs, "destaca principalmente la versatilidad del lenguaje iconográfico desplegado por la gente.” (Cortázar, 2014: 192). 
Es común que los memes, como herramientas de comunicación, estén cargados de contenidos que poseen un sentido o cierta relevancia para un grupo específico de personas o para la sociedad en su conjunto, cargados de ironía y burla (Vélez, 2012: 116), generalmente se reproducen haciendo uso de las imágenes y videos originales, así como modificando el mensaje o el texto

Los i-memes suelen utilizar "estructuras que repiten fórmulas tradicionales: el collage, la sátira, el chiste, la parodia, la caricatura, la viñeta, el juego de palabras, el absurdo, etc." (Alarcón, 2017: 144), empleando las nuevas herramientas digitales.

Destacan 5 características principales de los memes en internet, las cuales quedan explicadas a más profundidad en los siguientes párrafos: a. viralidad (Dawkins, 1989; Romero, 2015), b. humor (Pirandello, 2002; Alarcón, 2017), c. transtextualización (Genette, 1989) o su ramificación especifica de acuerdo con otros autores (Knobel y Lankshear, 2006; Milner, 2013; Shifman, 2014; Ruíz, 2018), la intertextualidad, d. yuxtaposición anómala (Knobel y Lankshear, 2006; Arango, 2017) y e. templatización (Sandoval, 2017: 4).

a. Viralidad: Se considera que un objeto digital se vuelve viral cuando es ampliamente difundido a través de la red. Estos componentes culturales tienen como objetivo principal propagarse, es decir ser replicados o imitados, "los memes pueden recorrer un largo camino, pero siempre deteniéndose escasos minutos o segundos en cada parada" (Castagno, 2013: 15), por ello buscan provocar sensaciones en los cerebros de quienes impactan mediante el humor.

b. El humor es definido por la RAE como el "modo de presentar, enjuiciar o comentar la realidad, resaltando el lado cómico, risueño o ridículo de las cosas". Los memes se nutren de las experiencias y situaciones cómicas, divertidas, anecdóticas o ridículas que experimentan los individuos cotidianamente. Es por ello, por lo que, para comprender su significado, es necesario conocer "primero el universo de experiencias a su alrededor" (Castagno, 2013: 14). Cuando los individuos son capaces de comprender el significado de un meme, se sienten seguros y adquieren un sentido de pertenencia a una comunidad, "satisfaciendo algunas de las mayores necesidades psicológicas de los seres humanos" (Malo, Medrano y Uriarte, 2010: 1).

c. Transtextualidad (Intertextualidad): En su libro Palimpsestos: la literatura en segundo grado, Genette (1989) explicó la transtextualidad como todo lo que pone al texto en relación, manifiesta o secreta, con otros textos". En el caso de los memes, no necesariamente se refiere a la lengua, más bien es la relación que suele haber entre ciertas "apropiaciones iconográficas" (Sandoval, 2017: 4) como puede ser el uso de material visual originado en producciones audiovisuales o de diferentes fuentes con el texto que se le añade para cambiar el sentido del mensaje. Knobel y Lankshear (2007) explican que la mayoría de los memes exitosos realizan una suerte de remisión hacia elementos de la cultura popular (películas, caricaturas, aparatos de moda, marcas o costumbres) para lograr ese reconocimiento dentro del "espacio de afinidad".

d. Yuxtaposición anómala: De acuerdo con la RAE, se refiere a la "unión de uno o más elementos gramaticales contiguos del mismo nivel jerárquico y sin partículas intermedias que los relacionen”. Sin embargo, cuando se habla de "yuxtaposición anómala" en los memes, se refiere a la incongruencia que 
existe entre uno o más elementos (símbolos, imágenes, videos, texto, etc.) en un mismo cuadro (Ruíz, 2018: 1016).

e. Templatización: Se refiere al uso de plantillas de diseño disponibles en páginas web o aplicaciones conocidas como "generadores" para la creación y modificación de memes. Es así, por lo que la composición de los memes es familiar y reconocida entre los usuarios.

La inmediatez y ubicuidad de las redes sociales fomentan que los usuarios tengan una necesidad compulsiva de consumir nuevos contenidos continuamente, acelerando el proceso de "selección natural" de los memes y poniendo en riesgo su supervivencia:

tuvieron inicialmente un cierto potencial trasgresor al tener como objetivo expandir noticias de forma oficiosa, parodiar la realidad y recentrar al individuo en situaciones diversas, su generalización ha hecho que terminen siendo imágenes canónicas. De forma que la realidad ha dejado de ser interesante por tiempo sostenido y lo que deseamos inmediatamente después de ella es ver las nuevas imágenes que sobre ella circulan en la red. Nuestra sed por la novedad se ha vuelto constante. (Cortázar, 2014: 195)

Los medios de comunicación tradicionales, especialmente la televisión, suelen hacer eco de los memes de moda para comunicar los sucesos de actualidad, convirtiendo a éstos en elementos noticiosos y ayudando así al proceso de viralización.

Es posible analizar un acontecimiento específico a través de los memes. Ejemplos de esto son las representaciones que hacen los usuarios de encuentros deportivos, académicos, series de televisión, crisis empresariales, debates políticos, declaraciones de líderes locales o internacionales, entre otros.

Son muchos los académicos que en la última década han sentido curiosidad por explorar el ingenioso mundo de los "i-memes", como impactan y representan la ideología de una comunidad. Estos estudios, generalmente se decantan por el análisis del contenido comunicativo de los propios memes (Lull y Neiva, 2011; Gómez, Fernández, Gómez y Fernández, 2013; Cortázar, 2014; García, 2014; Muñoz, 2014; Castañeda, 2015; Martínez, 2018), perspectiva de género (Ballesteros, 2016; Piñeiro y Martínez, 2016; Pérez, Provoste, Torres y Vásquez, 2017; ) el uso de los memes en la pedagogía (Arango, 2015; Vera, 2016; Gallego, 2018; Medina, 2018 ), en la política (González, 2013; Rowan, 2015; Meso, Mendiguren y Pérez, 2016; Martínez y Piñero, 2016 y 2017), en la construcción de la opinión pública (Cárcamo, 2015; Romero, 2015; Ayuso, 2018; Guano, 2018) entre otros. Sin embargo, hasta la fecha no se ha encontrado bibliografía relacionada con el estudio de los memes producidos a partir de conflictos diplomáticos o internacionales.

\section{Objetivos y Metodología.}

El objetivo del presente artículo es aportar una visión del uso de las figuras meméticas en el campo de las relaciones internacionales, analizando cómo, en un conflicto internacional de menor escala (el pequeño conflicto diplomático que surgió entre México y España en marzo del 2019), las partes (en este caso, los propios ciudadanos) realizan críticas y dan su opinión mediante el uso de memes. 
Además, se busca analizar, si es que existe dicha participación, si ésta es de carácter crítica, es decir, si los usuarios que participan en el consumo, intercambio y edición de los memes, lo hacen de forma analítica, reflexiva y con cierto criterio, o si, por el contrario, la concepción de dichas actividades es de carácter lúdico o de entretenimiento.

También, se buscará descubrir opciones que permitan a las instituciones públicas y gubernamentales, como las cancillerías de relaciones internacionales, añadir estos elementos culturales dentro de sus estrategias comunicativas digitales, para hacer llegar sus mensajes a su público objetivo, gracias a sus cualidades retóricas, por consecuente, a su capacidad de persuadir (Ruíz, 2018: 995).

El presente trabajo de investigación utiliza una metodología híbrida, la cual combina un estudio de caso por considerarlo "una herramienta valiosa de investigación" (Martínez, 2011: 167) que permite profundizar en la observación de la conducta de los implicados en el estudio y un análisis multimodal del discurso, por permitir el estudio conjunto del lenguaje y otros medios como pueden ser imágenes, recursos audiovisuales, entre otros (O'Halloran, 2012: 76).

Los estudios de caso se han convertido en un método de estudio destacado para la investigación del comportamiento social (Martínez, 2011: 174), ya que aportan una visión amplia del problema o tema a tratar. Se puede incluir al presente estudio dentro de la orientación del interaccionismo simbólico planteado por Schwartzman en 1993 (Reyes, 1999: 78)

Los casos de investigación suelen comprender una amplia visión complementaria. De acuerdo con Yin (1994:13), un estudio de caso es:

una investigación empírica que estudia un fenómeno contemporáneo dentro de su contexto de la vida real, especialmente cuando los límites entre el fenómeno y su contexto no son claramente evidentes. (...) Una investigación de estudio de caso trata exitosamente con una situación técnicamente distintiva en la cual hay muchas más variables de interés que datos observacionales; $y$, como resultado, se basa en múltiples fuentes de evidencia, con datos que deben converger en un estilo de triangulación; y, también como resultado, se beneficia del desarrollo previo de proposiciones teóricas que guían la recolección y el análisis de datos.

El estudio procura ser descriptivo-interpretativo, desde una perspectiva cualitativa, ya que pretende identificar los elementos claves o variables que inciden en el fenómeno de la participación ciudadana en conflictos diplomáticos, mediante el uso de objetos digitales, en particular, los memes. Recurriendo inevitablemente a la etnografía digital, por ser el espacio en donde se consumen, comparten y adapta el objeto de estudio.

Para la selección de la muestra a analizar se ha escogido trabajar con la ayuda de diferentes plataformas entre las que destacan: Google.com, Twitter, Facebook y Whatsapp por ser los sitios web preferidos por los usuarios, tanto de México como de España, para interactuar, enterarse de los acontecimientos políticos e internacionales y donde son capaces de expresar su opinión de acuerdo con el último informe de We are social y Hootsuite: "Digital in 2019".

Se han monitoreado los sitios anteriormente mencionados en busca de memes en el periodo comprendido entre el 25 de marzo (fecha en la cual el presidente López Obrador revela la existencia de la carta) y el 25 de junio, ya que se quiso dejar un margen de 
tiempo relativamente amplio desde la última publicación encontrada referente al tema (13 de junio), por ver si el debate recobraba fuerza en la conversación online.

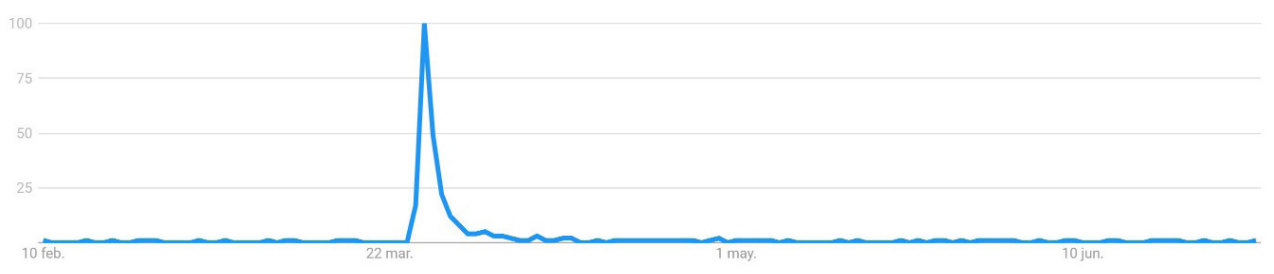

Gráfica 1: "Carta de AMLO a España"

Fuente: Google Tendencias. Consultado en Julio de 2019.

Para ayudar a filtrar la búsqueda y garantizar la pertinencia de los memes encontrados se han utilizado hashtags como \#perdonEspaña, \#EspañaDebeDisculparsePor, \#AmloHaceElRidiculoMundial y \#AMLOnoMeRepresenta con sus diversas variantes, además de búsquedas sencillas en Google.

En total, se encontraron 90 memes originales, de los cuales surgen replicas considerablemente similares, ya que presentan variaciones en alguna de las palabras o imágenes, sin cambiar el significado del contexto en general. Para la realización del análisis multimodal del discurso se utilizó la batería de preguntas propuestas por Michele Knobel y Colin Lankshear para el análisis de memes online, basados en tres ejes principales: sistema referencial o de ideas, sistema contextual o interpersonal y sistema ideológico o visión del mundo (Knobel y Lankshear, 2007: 207).

Para resaltar los resultados más destacados de la investigación, se han seleccionado 15 memes por considerarse que representan a los tres ejes mencionados anteriormente y que, al mismo tiempo, están cargados de referencias importantes al debate y que son diversos entre sí. Así mismo, no se han seleccionado para esta muestra aquellos memes que por su contenido físico o lingüístico sean muy similares.

Con todo lo anterior mencionado, se intentarán resolver las siguientes preguntas de investigación:

- ¿Qué tipo de mensaje (reiterativo, de posicionamiento a favor o en contra, crítico, lúdico) transmiten los memes analizados?

- Si hay critica, ¿qué se está criticando? y ¿cómo y dónde se manifiesta?

- ¿Qué características de los memes se destacan o se encuentran con mayor facilidad en el corpus analizado?

- ¿Quiénes son los protagonistas de los memes? ¿Cómo son representados?

- ¿Qué tipo de elementos culturales son rescatados para construir la crítica o el humor? ¿De dónde provienen?

\section{Caso de estudio: \#PerdónEspaña.}

El 25 de marzo de 2019, el presidente mexicano Andrés Manuel López Obrador (AMLO) publicó un controvertido video en sus cuentas de redes sociales que en pocas horas propicio un debate internacional diplomático y mediático. 
En el video, con una duración de 6 minutos y 56 segundos, aparece AMLO, acompañado de su esposa, la primera dama, Beatriz Gutiérrez Müller, frente a la zona arqueológica de Comalcalco, en Tabasco, la cual data del siglo VI o VII, de acuerdo con las explicaciones del lugar que el mismo presidente aporta.

El motivo de la publicación es la conmemoración de la batalla entre los españoles y los mayas-chontales que tuvo lugar 500 años atrás. Es decir, el encuentro de los dos mundos, al que el presidente tacha de "invasión" por parte de los españoles a los pueblos nativos.

La polémica estalló cuando AMLO anuncia en el video que ha enviado una carta al monarca español, Felipe VI y al Papa Francisco solicitándoles que pidan perdón por la violación a los derechos humanos de los pueblos indígenas durante la conquista:

envié ya una carta al rey de España y otra carta al Papa para que se haga un relato de agravios y se pida perdón a los pueblos originarios por las violaciones, a lo que ahora se conoce como, derechos humanos" AMLO (Twitter, 25 de marzo de 2019) https://witter.com/lopezobrador_/status/1110274329319743488

Él y su esposa adelantan también que en el 2021 se celebrará el bicentenario de la Independencia de México y que éste deberá de ser el "Año de la reconciliación histórica”, es por lo que será necesario que España y la Iglesia católica pidan perdón.

Tan solo 24 horas después de su publicación, el video había alcanzado 585,000 views, 20,000 me gusta, 6,200 shares y más de 5,000 comentarios de acuerdo con la propia cuenta de Twitter del mandatario y por supuesto, voces a ambos lados del Atlántico han querido dar su opinión acerca de si "España debe pedir perdón o no".

El gobierno español se vio en la necesidad de enviar un comunicado oficial por medio del Ministerio de Asuntos Exteriores y Cooperación (MAEC), en el cual respondía lamentando que se hubiera hecho público el contenido de dicha carta y oponiéndose a pedir perdón. Haciendo hincapié en que México y España han mantenido desde siempre, una estrecha relación de amistad, enfatizando su deseo de mantener las relaciones de amistad en asuntos de cooperación importantes para ambos países.

Los medios tradicionales locales, nacionales (de ambos países) e internacionales como los periódicos offline y online, la radio y la televisión hicieron eco de la "carta enviada al rey" y por supuesto, las redes sociales se incendiaron con la polémica.

Personajes públicos de la talla de Mario Vargas Llosa o Pérez Reverte, líderes políticos de ambos países, historiadores, intelectuales, entre otros, también dieron su opinión sobre la diputa, principalmente a través de sus redes sociales. En la presente investigación se evitará profundizar en opiniones a favor o en contra, ya que el principal objetivo es analizar el contenido de los memes que surgieron y se popularizaron alrededor del conflicto.

\section{Análisis de memes}

Como ya se ha explicado con anterioridad, los memes generalmente sufren variaciones al ser transferidos de un individuo a otro, es decir "no son replicadores de alta 
fidelidad, la transmisión de los memes se ve sometida a una mutación constante, y también a una fusión" (Dawkins, 1989: 274).

Esta "mutación constante", se ve acrecentada por las herramientas que ofrecen las tecnologías digitales, es decir, una serie de diversas aplicaciones que permiten modificar rápidamente el mensaje de un meme para adaptarlo a una situación o un contexto distinto.

Un punto relevante en la construcción del mensaje, a través de los memes, es que éstos generalmente basan sus argumentos en elementos culturales y visuales para manifestar las críticas y el humor.

Los memes que a continuación se analizarán han sido seleccionados debido a los medios visuales que utilizan, las representaciones culturales de las que se acompañan y la relación que tienen con el conflicto al que hace referencia el presente artículo.

- De una vez ya encarrerado reclama a la corona de Holanda de que no fue penal.

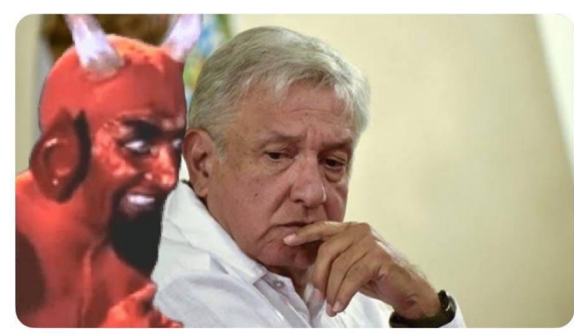

Figura 1

\section{AHORA DI QUE DONALD TRUMP DEBERÍA DISCULPARSE POR CUANDO NOS QUITARON LA MITAD DEL PAÍS...}

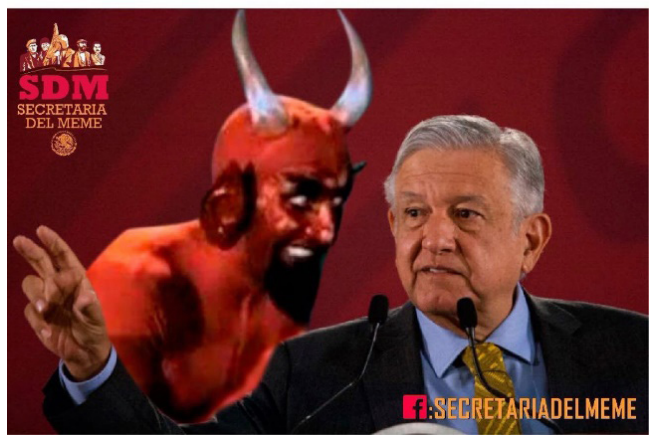

Figura 2

\section{\#1 Trotsky consejero}

En su origen, este meme rescata una imagen proveniente de una película mexicana navideña, Santa Claus, considerada en sí misma una sátira producida en 1959, en la cual el diablo aparece tentando a una niña.

Durante el transcurso de la película, el mismo Lucifer ordena a un diablo, de nombre Precio, que consiga influir en los niños para que se porten mal y de esta manera Santa Claus sería incapaz de cumplir con su misión. Además, el apodo del actor que interpretaba el papel de Precio era Trotsky. Se cree que por la barba de perilla que utilizaba, similar a la del revolucionario izquierdista ruso que se refugió en México.

El imaginario colectivo mexicano relaciona al diablo de esta película con la intención de "pervertir" a seres inocentes como los niños. En el caso de los memes de las figuras 1 y 2 se ha sustituido la imagen de la niña por la del actual presidente de México, AMLO, responsable inicial del desencadenamiento del debate; haciendo la alusión de que sus actos son influenciados por las fuerzas del mal y aprovechan para hacer una crítica a la clara postura socialista del presidente.

Ambos memes utilizan situaciones del pasado de la historia de México para añadir el tono hilarante al mensaje. El primero sucedió en el ámbito deportivo cuando México fue expulsado del mundial en 2014, tras un polémico penal a favor del equi- 
po holandés, que terminó por darle la victoria. Mientras que el segundo texto, hace referencia a la guerra surgida entre EE. UU. y México en la cual, el segundo país tuvo que ceder más de la mitad de su territorio para poner fin al conflicto a cambio de una compensación ridícula. El colectivo nacional aún sigue haciendo referencia a estos desagradables momentos que ha tenido el país a lo largo de su historia.

Las figuras analizadas parodian que sería igual de absurdo solicitar a Holanda o a EE. UU. que pidieran perdón por hechos que no representan ningún problema real en el presente del país.

En ambas figuras se puede apreciar cómo "el texto produce (inventa) un significado enteramente nuevo" (Barthes, 1986: 23) al que se puede representar en la fotografía del meme.

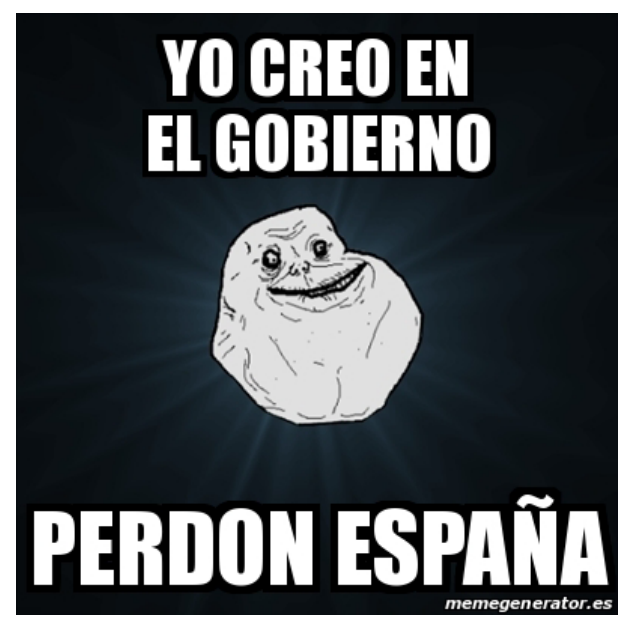

Figura 3

\#2 Forever alone creyente

Esta macro imagen es una evolución de una de las figuras más clásicas dentro de los memes. Tiene su origen en 2009 y forma parte de la serie de "caras de ira" producida por 4chain. "Por siempre solo" en español, es representado por un personaje cómico de ira utilizado para expresar soledad y desilusión hacia la vida.

Normalmente, va acompañado de texto que ayuda a representar rasgos característicos de "algún personaje común". En este caso forever alone, encarna a los seguidores del actual gobierno de México, dando a entender, mediante la ironía, que son muy pocos y suelen estar aislados. Finalmente, en la parte inferior del meme, destaca "perdón España", rechazando la petición de AMLO al gobierno de España de pedir perdón por los hechos ocurridos durante la conquista. 


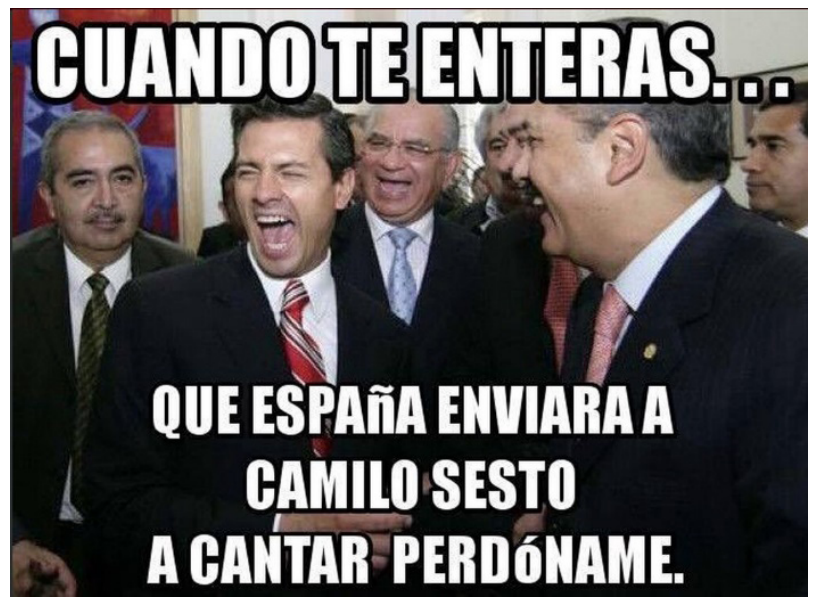

Figura 4

\#3 Peña Nieto, el graciosillo

Los memes se han convertido en la mejor herramienta de las sociedades modernas para expresar el descontento que tienen con sus gobernantes y políticos. El expresidente mexicano no ha sido la excepción, por el contrario, durante los seis años que duró su mandato, se produjo una innumerable cantidad de memes, ridiculizándolo y subestimándolo, debido a la penosa gestión que realizó durante su gobierno. La mayoría de ellos reproducen la imagen que tiene el colectivo mexicano de desconfianza hacia las instituciones.

En la figura 4 se puede observar una imagen que fue tomada durante un receso en la presentación de sus proyectos en el foro de la Fundación Colosio en Chihuahua, en la que el exmandatario aparece riéndose a carcajadas con el político priista Manlio Fabio Beltrones, quien se enfrenta a cargos por desvió de fondos públicos, durante las campañas políticas del 2016 y que ha sido utilizada en diversas ocasiones para la creación de memes.

La imagen se encuentra acompañada de un texto superpuesto que hace alusión a la reacción que puedes tener cuando descubres que algo va a pasar, dando a entender que el único perdón que va a obtener México por parte de la corona española va a ser que un cantante español famoso actúe en el país cantando una canción titulada: "Perdóname".

Dentro del imaginario de los consumidores mexicanos de redes sociales y memes, esta imagen representa lo irrisorio de la carta enviada por AMLO, al mismo tiempo que enfatiza la desconfianza del pueblo hacia sus gobernantes, ridiculizando sus iniciativas fuera de lugar y faltas de reflexión y conocimiento de la historia verdadera del país. 


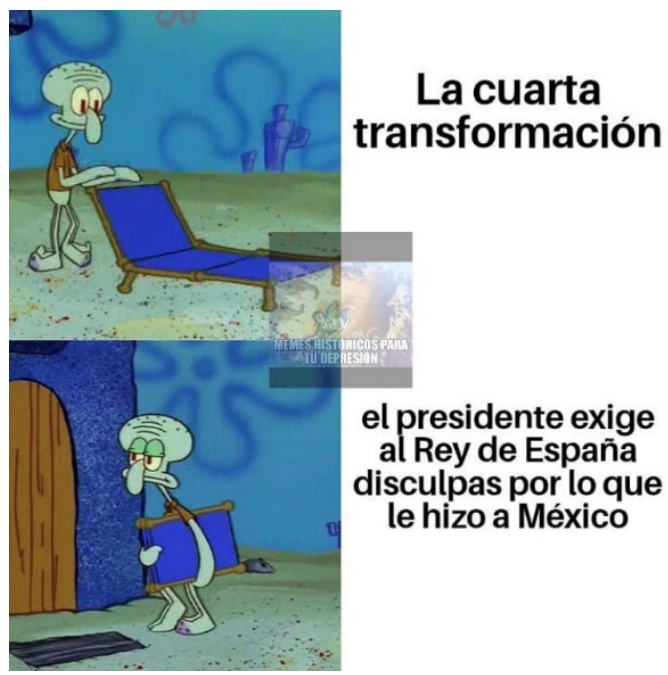

Figura 5

\#4 Calamardo desilusionado

Este formato de meme, conocido como "drakeposting", se basa en colocar imágenes de reacción secuencial una encima de otra y acompañar cada una de ellas de un texto.

En este caso en particular, se utilizan dos imágenes obtenidas de la conocida serie de televisión infantil Bob Esponja. En la primera imagen, uno de los personajes, $\mathrm{Ca}$ lamardo, aparece colocando una tumbona fuera de su casa con singular entusiasmo, y en la segunda se observa al mismo personaje regresando decepcionado a su casa con la tumbona bajo el brazo.

Generalmente, este conjunto de imágenes se utiliza para describir situaciones en las que algo emociona o esperanza y posteriormente ocurre un evento que desilusiona por completo. En este caso, hace referencia a la promesa de cambio y mejora que hizo el mandatario mexicano AMLO desde su campaña presidencial, conocido como "Cuarta transformación", que sedujo a muchos de sus votantes y que, debido a las acciones que está tomando el presidente, como es el caso de la carta a la corona española, ha desilusionado y hecho que la desconfianza vuelva al pueblo.

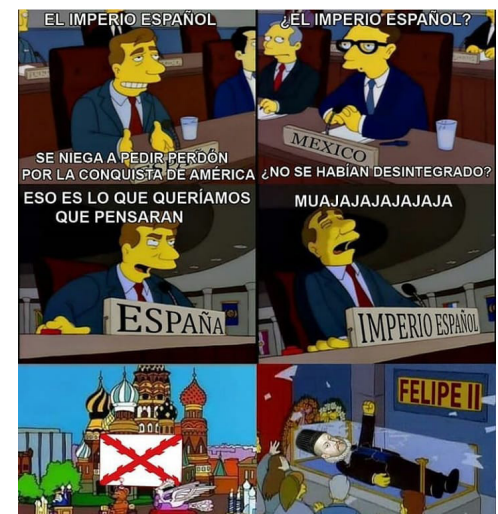

Figura 6

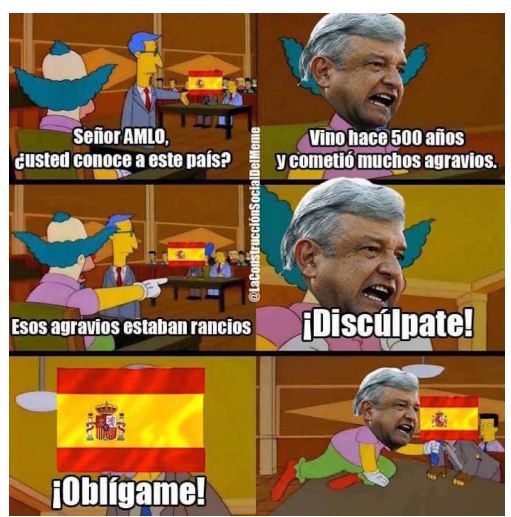

Figura 7 


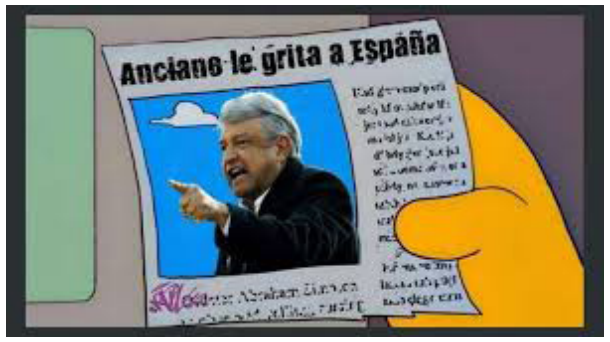

Figura 8

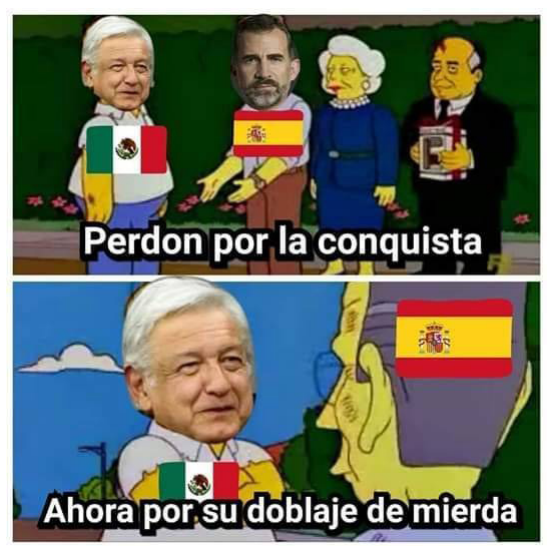

Figura 9

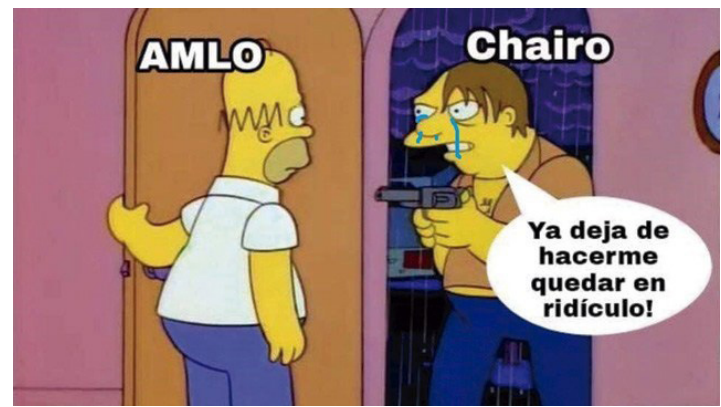

Figura 10

\#5 Los Simpson (Figuras 6-10)

Los Simpson es una serie de televisión que trata sobre una familia de clase media estadounidense con capítulos de corta duración en los que ridiculizan la cultura norteamericana y hacen reflexionar al espectador mediante la comedia. Sus 30 temporadas se han convertido en la inspiración de un sinfín de memes alrededor del mundo, especialmente ante situaciones ridículas.

El pequeño conflicto diplomático entre México y España ha hecho que los creadores de memes tomaran como referencia algunas imágenes obtenidas de varios capítulos de esta serie para mofarse de la petición de AMLO. A continuación, se analizarán algunos de los memes que fusionan el entretenimiento que provee la serie norteamericana y la ridiculez del discurso del actual gobierno mexicano.

"Eso es lo que queríamos que pensaras" es la inolvidable frase que utiliza, en uno de los capítulos de Los Simpson, el embajador ruso cuando revela que la caída de la Unión Soviética fue una artimaña. En la figura 6, se hace una parodia de la atemporalidad del pedimento de López Obrador, debido a que las afrentas por las que se hace, ocurrieron hace cinco siglos, cuando España aún no estaba conformada como se conoce hoy en día. Además, existe una mutación de este mismo meme en dónde se sustituye el "Imperio Español" por "Imperio Mexica", el cual, a modo de sarcasmo, explica que el actual México y los pueblos originarios a los que se refiere AMLO en su carta, han dejado de existir hace más de 500 años, ya que, México y los mexicanos son producto del mestizaje de indígenas con españoles. 
“Oblígame”. La serie de imágenes obtenidas del capítulo 18 de la temporada 7 de Los Simpson, que se puede apreciar en la figura 7, ha sido utilizada para la realización de varios memes. En la serie, el abogado de Chester (el vagabundo que está reclamando los derechos de la empresa Rasca y Pica) le pregunta durante el juicio al payaso Krusty si conoce a Chester y éste responde que sí, que lo contrató para pintar la reja y que nunca lo hizo. A lo que el vagabundo responde que no la pintó porque le pagó con comida rancia. Entonces, Krusty le dice que se la pinte y Chester le responde con la famosa frase "Oblígame". En el meme se sustituye la cara de Chester por la bandera de España, representando a la nación y al payaso Krusty con la cara de AMLO. Cuando le preguntan al presidente que sí reconoce a España, contesta que es un país que cometió muchos agravios en México hace 500 años y que deben disculparse burlándose de la carta que envió el mandatario al rey de España. A lo que España contesta que los agravios a los que se refiere son pasados, fuera de lugar y anticuados.

Se hace una clara referencia a los lazos de amistad, fraternidad y cooperación que existen entre México y España desde hace muchos años, además de remarcar la idea de que los acontecimientos por los que el presidente mexicano urge a España a pedir perdón, sucedieron varios siglos atrás y no es productivo, para ninguno de los dos países, abrir heridas cerradas.

"Viejo hombre le grita a la nube". Esta imagen rescatada de un capítulo de Los Simpson del 2002, en la que el abuelo Simpson aparece en un titular del periódico gritando y apuntando a una nube, ha sido modificada en internet para hacer críticas sobre diversas temáticas, basándose en el modelo (X) grita a (Y). En la figura 8 , se hace una recomposición de esta imagen, colocando una fotografía de AMLO apuntando con el dedo índice hacia el frente y en el titular del periódico se puede leer la frase "Anciano le grita a España". Este meme hace referencia a las críticas provenientes de los detractores del presidente de que la vejez lo ha desequilibrado mentalmente, es por ello por lo que sus decisiones son tan poco acertadas.

Este meme representa un claro ejemplo de yuxtaposición ya que se organiza mediante un sistema dual (signos y lenguaje), goza de mensajes connotativo y denotativo y los textos agregan información que no está implícita en la imagen (Arango, 2017: 308).

"Malos vecinos". La figura 9 corresponde a un par de imágenes secuenciales obtenidas del treceavo episodio de la séptima temporada de Los Simpson, en las cuales el expresidente Bush se ve obligado a disculparse con su vecino Homer, por una serie de rencillas que surgen entre ellos, al convertirse en vecinos. En la primera imagen, aparece Felipe VI disculpándose con AMLO por la conquista y en la segunda AMLO le exige disculpas por doblar todas las series y películas del inglés al español.

Este meme hace referencia a la herencia histórica española de doblar las películas primero, para que pudieran ser comprendidas por un amplio público y segundo, por la ley promulgada por Franco, en la que se obliga a que todas las películas sean habladas en español con un propósito meramente propagandístico, por un lado, para robustecer el sentimiento de nacionalismo y por el otro, para censurar contenido indeseable.

Esta costumbre que se mantiene principalmente por un propósito económico, incomoda a un gran público, principalmente en Latinoamérica, dónde están más acostumbrados a consumir los productos audiovisuales originales o subtitulados. La crítica principal es que se alteran elementos primordiales de las series o películas, perdiendo una parte esencial de las historias. 
Se puede apreciar claramente la intertextualidad en cuestión de que se utilizan referencias cruzadas, empapadas de humor seco, la primera relacionada con un evento aislado (solicitud de perdón del presidente de México) y la segunda forma parte de la cotidianidad de los usuarios de redes sociales de Latinoamérica y España de criticar los doblajes en español realizados con acentos diferentes a los propios. De hecho, es posible encontrar un sinfín de memes relacionados con los doblajes.

"Todos contra AMLO" en la figura 10 se observa una captura de pantalla obtenida de la temporada 5, del capítulo 4, en la que aparece Barney Gumble, el mejor amigo de Homer, pensado por su creador para ser "lo más patético posible" representando a "los chairos" con una pistola apuntando a Homer, quien personifica a López Obrador.

La palabra "chairo" viene usándose en México, desde hace varios años para referirse, de forma ofensiva, a aquellas personas que comulgan con ideas socialistas-anarquistas, llevando el sentimiento de nacionalismo al extremo y manifestándose rotundamente en contra de la derecha y de la globalización. Además, incluye la concepción de que "los chairos" no se comprometen con sus causas, es decir, actúan dependiendo de sus conveniencias, no les gusta trabajar, actúan de forma necia y sin sentido. En general, todos los seguidores y defensores de AMLO son considerados "chairos".

En el meme se puede ver un globo con la frase "ya deja de hacerme quedar en ridículo" señalando al "chairo", ridiculizando precisamente ese comportamiento de defender absolutamente todas las ideas e iniciativas del presidente, sin ninguna clase de raciocinio. En este caso, se burlan de esa parte de la población que concuerda con la "absurda" idea de que España le pida perdón a México por lo ocurrido durante la conquista, sabiendo que hay temas más importantes para el desarrollo del país, a los que el presidente no está atendiendo por mantener su narrativa de resentimiento que le sirve para tener a su audiencia cautiva.
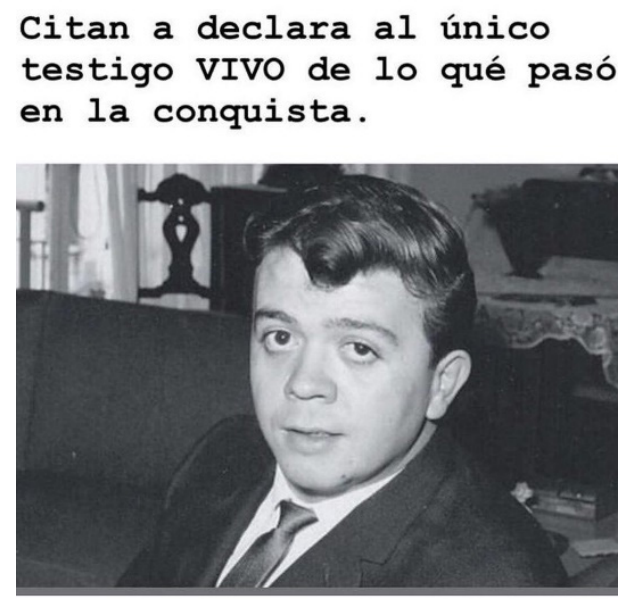

Figura 11

\#6 Chabelo

El actor Xavier López, conocido popularmente como Chabelo por protagonizar, por más de 48 años, el papel de un niño como presentador de un programa infantil en la televisión mexicana, es un ícono de la cultura del entretenimiento en Latinoamérica y su longevidad, aparentemente interminable, lo ha convertido en el personaje 
de memes más emblemático para representar la inmortalidad, es decir, para ponerlo como testigo de cualquier situación ocurrida en la antigüedad.

En esta ocasión, y gracias al debate generado por la petición de AMLO a España y al Vaticano, los internautas mediadores del conflicto han querido llamar a testificar a este personaje eterno y tan apreciado por toda la sociedad mexicana, ya que, durante años, unió todos los domingos por la mañana a familias. Por lo que además el meme de la figura 11 resulta conciliador ante la discordia suscitada.

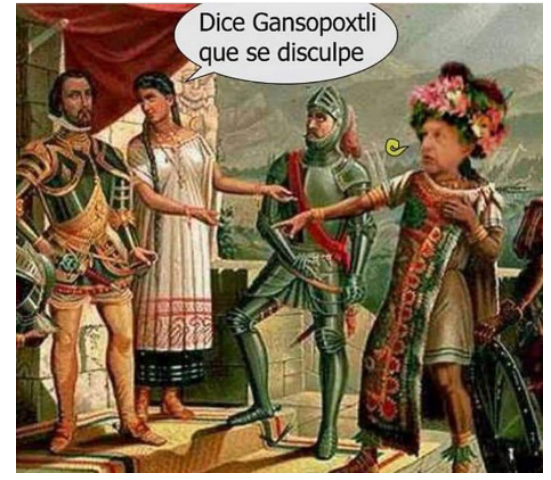

Figura 12

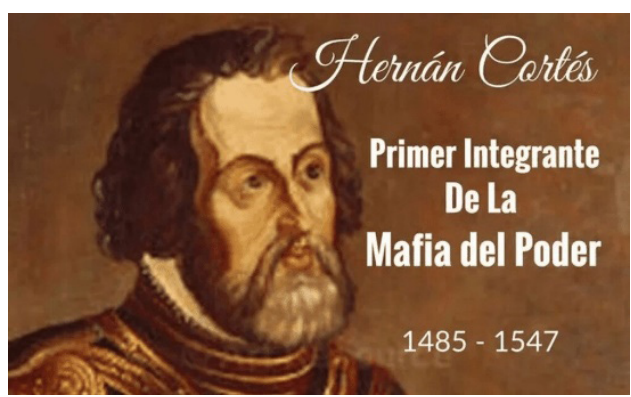

Figura 13

\section{\#7 Reviviendo a Hernán Cortés}

La presente bilogía de memes tiene como común denominador a su protagonista, en este caso, un personaje histórico, responsable en parte de la conquista de México, Hernán Cortés.

En la figura 12 podemos apreciar cómo, en algunas ocasiones, los memes utilizan juegos de palabras ingeniosos como elementos extralingüísticos para satirizar situaciones, mientras que en muchos casos se ayudan de herramientas gramaticales para crear nuevos significados, que le agregan humor a la crítica.

El acrónimo encontrado es "Gansopoxtli", una clara combinación de la palabra "ganso" y "Huitzilopoxtli". La primera, se refiere claramente a la frase popular que utilizó el mandatario mexicano en su toma de protesta "me canso ganso" para ganar credibilidad y acercarse al pueblo. Este guiño, suscitó infinidad de burlas en las redes sociales, sin embargo, muchos expertos lo han analizado como parte de la estrategia comunicativa popular. Mientras que la segunda hace alusión al dios más importante de los mexicas, pueblo dominante a la llegada de los españoles, es decir durante la conquista.

En el meme se observa a la Malinche ${ }^{2}$ traduciéndole a Hernán Cortés los deseos de "Huitzilopoxtli" representado por AMLO. De tal manera, que el mensaje que se transmite es que el presidente se ve a sí mismo como el dios o el salvador del pueblo bueno y oprimido por el sistema político tradicional.

En la figura 13, se puede encontrar "una parodia de la fórmula recurrente heredera de la tradición enciclopédica, de colocar junto a la biografía, citas, ideas, obras, etc.

La malinche fue una mujer que desempeñó un papel fundamental para que la conquista se llevara a cabo, sirvió de traductora y consejera de Hernán Cortés, además de su esposa. Históricamente, siempre ha sido un personaje controvertido, para muchos es sinónimo de traición a la patria, para otros es la victima principal de la conquista y también es considerada la madre del mestizaje. 
de un personaje, su retrato" (Alarcón, 2017: 128). Este tipo de meme no busca burlarse del personaje referido, en este caso Hernán Cortés.

La comicidad está en el mensaje "la mafia del poder", la consigna que ha utilizado durante décadas el presidente López Obrador para referirse a los anteriores gobernantes del PRIAN y algunos empresarios que han gozado de privilegios a costa del pueblo mexicano. Es frecuente escuchar durante sus discursos que "acabará con la mafia del poder", sin embargo, los ciudadanos que no lo apoyan, consideran que es un montaje para conseguir mantenerse en el poder. En el meme se deduce la mofa hacia esta idea.

Para la oposición, como AMLO es incapaz de acabar con la mafia del poder, porque de hecho él la representa en muchos aspectos, ha tenido que recurrir al pasado para continuar con su discurso propagandístico y demagógico de "los buenos" contra "los malos" y de que él es el justiciero.

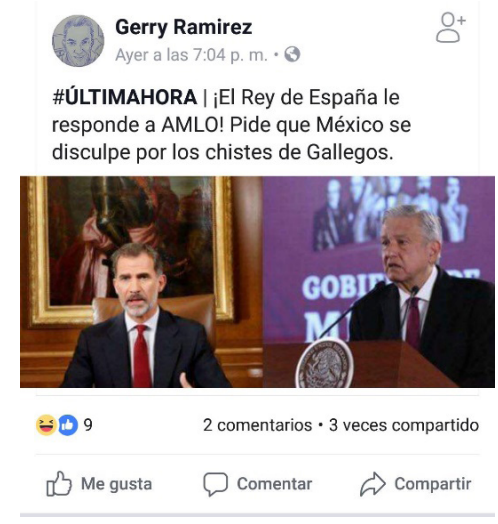

Figura 14

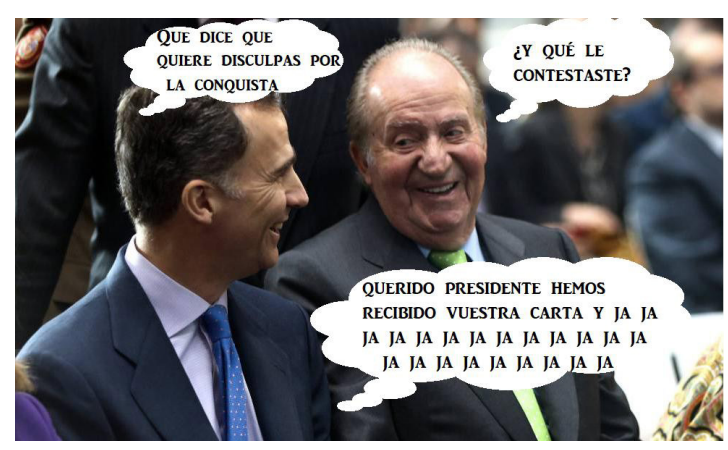

Figura 15

\#8 El rey entra en escena

En la figura 14 se puede observar por un lado la imagen del rey Felipe VI de España, obtenida del video del discurso que dio el pasado año acerca de la crisis de Cataluña y por el otro, la fotografía de AMLO, en alguna de sus tradicionales conferencias de prensa "mañaneras" que tienen lugar desde el 1 de diciembre de 2018, como parte de su estrategia comunicativa para gobernar.

El humor está presente una vez más en el texto, primero se utiliza un formato de sobra conocido cuando los medios tradicionales de comunicación dan noticias, encabezado corto acompañado de las palabras "última hora" unidas por un "hashtag". Estas palabras son normalmente usadas para transmitir información extraordinaria, fuera de lo común y generalmente interrumpen la programación regular. Lo hilarante es la última frase donde dice que el rey exige a México que se disculpe por los chistes de gallegos.

Pese a que los gallegos son personas naturales de Galicia, una región de España, durante años se les ha conocido así en Latinoamérica a los españoles, convirtiéndose en los protagonistas de millones de relatos orales populares que se mofan de este gentilicio. Inclusive hasta hace no muchos años (2001), una de las definiciones que daba la RAE de los gallegos en Costa Rica era "tontos" y "tartamudos" debido a la masiva producción de chistes relacionados con este gentilicio. 
Se distingue una "explicita manipulación del contenido visual y audiovisual masivo" (Shifman, 2014: 118) reapropiándose de las imágenes originales y añadiéndoles elementos culturales reconocidos por mexicanos y españoles para satirizar la petición de López Obrador de que España debía pedir perdón a México.

En la figura 15 se observa una imagen donde aparece el rey emérito de España junto con el actual, intercambiando miradas y sonrisas como gesto de complicidad, se agregan globos para generar la sensación de que están teniendo una conversación. Este tipo de meme es considerado meme viñeta por su origen en los comics.

Su mensaje principal es burlarse de la carta petición de AMLO. Aparecen en la imagen ambos reyes por ser la máxima autoridad de España, cuya función principal es la de arbitrar y moderar el funcionamiento de las instituciones españolas. De tal manera que se da a entender que nadie se toma en serio la figura del mandatario mexicano.

Utiliza el formato de una carta formal en cuanto a estructura, elementos y redacción en la primera frase y posteriormente agrega la palabra "ja" en repetidas ocasiones, la reproducción de la risa en español.

\section{Conclusiones}

La mayor parte de los memes encontrados son de naturaleza estática, es decir combinaciones de imágenes sacadas de su contexto original acompañadas de elementos lingüísticos, dándoles un nuevo significado aludiendo al conflicto diplomático analizado, aportando humor a la situación, mediante la manifestación de evidencia documentada de que claramente no puede ser cierto (Knobel y Lankshear, 2007: 216).

Se puede apreciar que los usuarios crean, difunden y comentan los memes principalmente como forma de entretenimiento. Sin embargo, detrás de la batería de memes analizados se encuentra la necesidad de realizar una dura crítica hacia el gobierno del presidente López Obrador y su falta de compromiso para resolver los problemas reales que enfrenta el país.

A pesar de lo anterior, también se destacan mensajes que parodian otras realidades que nada tienen que ver con la diplomacia y la política exterior como, por ejemplo, el tema de los doblajes de las series y películas o el deporte.

Sin duda alguna, el mensaje es repetitivo, utiliza el sarcasmo para expresar descontento e incredulidad ante la acción tan ridícula del mandatario de enviar una carta exigiendo disculpas al rey de España y al Papa por sucesos ocurridos hace cinco siglos y que en nada afectan al panorama actual de México.

La crítica se manifiesta principalmente en el discurso multimodal encontrado los signos y el lenguaje de los memes. Por un lado, en las imágenes se encuentra la dimensión denotativa, mientras que en los textos se aprecia la connotación. Los memes que circulan por internet relacionados con el presente estudio de caso son concluyentes, la mayoría de los usuarios no apoyan el gobierno ineficiente de López Obrador y se avergüenzan de que sea su gobernante.

En el corpus analizado están presentes las características mencionadas en el marco teórico de la presente investigación: humor, intertextualidad, yuxtaposición, templatización y viralidad. Siendo las primeras tres las más destacadas, y sin duda alguna, presentes en todos los memes analizados.

Se encontró que la templatización está latente en los objetos digitales estudiados, sin embargo, no siempre provienen de las webs prediseñadas para modificar memes, 
por el contrario, surgen nuevas plantillas como puede ser el caso de imitar comics, la forma de dar alguna noticia por parte de los medios de comunicación tradicionales o la pretensión de simular contenido enciclopédico.

La viralidad está presente en la medida en la que se "reconocen ciertos tipos de acciones comunicativas" (Shifman, 2014: 99), es decir rasgos de estilo, estructura, e inclusive las temáticas.

Los principales protagonistas que se encontraron en el presente estudio son AMLO y el rey de España. Esto se entiende ya que son los actores internacionales que encarnan el debate bilateral en la vida real, suelen ser agregados mediante "collages" o Photoshop a personajes de películas o series, principalmente estadounidenses, aunque también hay alguna mexicana. Esto es lo que Limor Shifman (2014: 20) llama "mecanismo de reempaquetado", se pueden ver ejemplos en la figura 1, 2, 7, 8, 9 y 12. Generalmente los personajes de ficción mediante los que son representados tienen alguna característica en común con los que pretenden personificar.

En ocasiones se hace un remake de distintas imágenes procedentes de la televisión o el periódico, simulando un aviso importante de última hora, acompañado de un texto hilarante. Es ahí donde tiene presencia la parodia y el humor, como, por ejemplo, en la figura 14.

En varias ocasiones, los memes utilizan a personajes históricos como los protagonistas, mediante la utilización de imágenes obtenidas principalmente de monografías antiguas (ej. figura 12) y gracias a la yuxtaposición de símbolos, imágenes y palabras resignifican el contenido del material original.

Todos los memes analizados contienen elementos culturales de México y España, aunado a una clara influencia estadounidense, especialmente obras audiovisuales (films, series de tv, caricaturas, etc.)

Instituciones constitucionales, símbolos nacionales, acontecimientos deportivos, religiosos, costumbres y tradiciones como las pastorelas o los reyes magos, medios de comunicación, géneros musicales y patrimonio arquitectónico. Se hace alusión a personajes históricos que intervinieron en la conquista de México. Además, se mencionan subculturas presentes en México, como "los chairos".

El sarcasmo, humor y la parodia son ingredientes con un inmenso potencial de convencimiento, que influyen y condicionan las decisiones de quienes lo consumen. Si bien, con el análisis de los memes en un conflicto internacional no se puede percibir la postura de los países frente a dicha situación, es posible deducir la opinión y la actitud de los ciudadanos involucrados.

Los memes son pequeñas unidades que propagan elementos culturales de una comunidad offline y online simultáneamente a través de la actual sociedad de red de Castells (2001). Su estudio y utilización son vitales para comprender los procesos de socialización y de convivencia del siglo XXI.

A partir del presente estudio, se puede inferir que los memes, como elementos culturales de la comunicación digital del siglo XXI, podrían llegar a ser utilizados por los servicios de relaciones exteriores como parte de una estrategia de diplomacia cultural digital para fomentar el entendimiento entre las naciones y sus pueblos, además de contribuir a ejercer una mayor influencia en el mundo.

Sin embargo, tienen que ser muy cautelosos con el humor y sarcasmo que utilizan, ya que el significado del mensaje se puede malinterpretar dependiendo de la cultura local. 
Se trata de encontrar elementos culturales en común que ayuden a reforzar lazos de amistad, compartir conocimiento científico y social, buscando el desarrollo de ambas naciones. Es decir, combinar influencias internas y externas para alcanzar el entendimiento, estrechar relaciones y facilitar la comunicación con los nuevos actores del sistema internacional.

\section{Bibliografía}

Alarcón, V. (2017). Humorismo como creación y fortalecimiento de los vínculos en la sociedad red: el caso de los memes sobre filósofos. Revista De Comunicación, 16(1), 122-146. Recuperado de https://revistadecomunicacion.com/article/view/1011

Arango, L. (2015). Una aproximación al fenómeno de los memes en Internet: claves para su comprensión y su posible integración pedagógica. Comunicação mídia e consumo, 12(33), 109-131. Recuperado de http://revistacmc.espm.br/index.php/revistacmc/article/ view/677

Arango, L. (2017). Yuxtaposición, intertextualidad y humor en los memes de la Reforma en Telecomunicaciones en México. Revista de Estudios para el Desarrollo Social de la Comunicación, (15), 304-331. Recuperado de http://revista-redes.hospedagemdesites.ws/ index.php/revista-redes/article/view/482

Ayuso, J. (2018). Los memes en la prensa generalista: un nuevo género periodístico de opinión de la audiencia prosumidora. Repositorio documental de la Universidad de Valladolid. Recuperado de http://uvadoc.uva.es/bitstream/10324/34031/1/TFG_F_2018_72.pdf

Ballesteros, E. (2016). Circulación de memes en WhatsApp: ambivalencias del humor desde la perspectiva de género. Empiria. Revista de metodología de ciencias sociales, (35), 2146. Recuperado de http://revistas.uned.es/index.php/empiria/article/view/17167

Barthes, R. (1986). Retórica de la imagen. Lo obvio y lo obtuso, 29-47. Recuperado de http:// www.gramscimania.info.ve/2009_08_24_archive.html

Berlanga, I.; Mas, V.; Salvador, J. et Alberich, J. (2016). Facebook y la metáfora. La comunicación retórica en las redes sociales digitales. Signa: Revista de la Asociación Española de Semiótica, 25, 413-431. Recuperado de http://e-spacio.uned.es/fez/view/bibliuned:signa-2016-25-7160

Blute, M. (2008). Memetics and evolutionary social science. A MEMETICS COMPENDIUM, 223. Recuperado de http://citeseerx.ist.psu.edu/viewdoc/download?doi $=10.1 .1 .731 .4497 \&$ rep $=$ rep $1 \&$ type $=$ pdf\#page $=223$.

Bolívar, A. (2011). La ocupación mediática del diálogo político: el caso de las disculpas. Discurso \& Sociedad, 5(1), 41-70. Recuperado de http://www.dissoc.org/ediciones/v05n01/ DS5(1)Bolivar.pdf

Cárcamo, L. (2015). Memes y Opinión Pública ¿Una Relación Posible? Diálogos de la comunicación, (91), 8. Recuperado de https://dialnet.unirioja.es/servlet/articulo?codigo $=6845112$

Castagno, L. (2013). ¿Memes sólo diversión?: el fenómeno de los memes de internet más allá de la humorada (Bachelorss thesis, Facultad de Ciencia Política y Relaciones Internacionales). Recuperado de https://rephip.unr.edu.ar/xmlui/bitstream/handle/2133/5283/ TESINA\%20LUCIA\%20CASTAGNO.pdf?sequence $=3$

Cortázar, F. (2014). Imágenes rumorales, memes y selfies: elementos comunes y significados. Iztapalapa Revista de Ciencias Sociales y Humanidades, Núm 77, año 35. 191-214. Recuperado de: http://www.scielo.org.mx/pdf/izta/v35n77/2007-9176-izta-35-77-191.pdf 
Davison, P. (2012). The language of internet memes. The social media reader, 120-134. Recuperado de http://fall2015.veryinteractive.net/content/6-library/20-the-language-of-internet-memes/davison-thelanguageofinternetmemes.pdf

Dawkins, R. (1989). El gen egoísta extendido. Oxford University Press. UK.

Ellis, S. (1994). What are virtual environments? IEEE Computer Graphics and Applications, 14(1), 17-22. Recuperado de https://ieeexplore.ieee.org/abstract/document/250914/

Espino, L. (2019). Seis meses de AMLO presidente y seguimos sin entender por qué es tan popular. Letras libres. Recuperado de https:/www.letraslibres.com/mexico/politica/seismeses-amlo-presidente-y-seguimos-sin-entender-por-que-es-tan-popular

Eva, F. (2013) Caging, Selfcaging, Materialidad, Pirámides, Memes, Como Mejores Instrumentos De Análisis Geopolítico. ¿Una Aproximación Epistemológicamente Anárquica? Recuperado de https://ssrn.com/abstract=2373999 or http://dx.doi.org/10.2139/ ssrn. 2373999

Fonte, I. (2008). Un estudio pragmático del conflicto político mexicano-cubano (2004) en la prensa. Discurso \& Sociedad, 2(1), 86-114. Recuperado de http://www.dissoc.org/ediciones/v02n01/DS2(1)Fonte.html

Fuentes, R. (2019). LOLcat, O RLY?... Viaje nostálgico a aquellos primeros memes de Internet. El Mundo. Recuperado de https://www.elmundo.es/f5/comparte/2019/06/10/5cfaaabc21 efa0ed068b45ee.html

Gallego, J. (2018). El humor en el aula de español a través de los memes: un enfoque didáctico. TFM. UCrea. Repositorio abierto de la Universidad de Cantabria.

García, D. (2014). Las imágenes macro y los memes de internet: posibilidades de estudio desde las teorías de la comunicación. PAAKAT: Revista de Tecnología y Sociedad, (6). Recuperado de: https://www.redalyc.org/pdf/4990/499051555007.pdf

García, I. (2013-2014). Del meme al imeme, trascendiendo la dimensión lúdica. Entre textos, (5)15 1-9. Recuperado de http://entretextos.leon.uia.mx/num/15/PDF/ENT15-8.pdf

Genette, G. (1989). Palimpsestos: la literatura en segundo grado, Taurus. Madrid.

Gómez, A.; Fernández, A.; Gómez, A. G. \& Fernández, A. (2013). Memes, Rage-comics y Memenautas: Comunicación Efectiva en internet (Doctoral dissertation, Tesis). Recuperado de https://www.researchgate.net/profile/Alejandro_Gonzalez56/publication/308209716_ Memes_Rage-comics_y_Memenautas_Comunicacion_Efectiva_en_Internet/links/ 57de9cfb08ae72d72eac0f94/Memes-Rage-comics-y-Memenautas-Comunicacion-Efectiva-en-Internet.pdf

González, C. (2013). El discurso político de resistencia en las redes sociales: el caso de los memes desde una perspectiva crítica y multimodal. Contextos: Estudios de Humanidades y Ciencias Sociales, (30), 37-48. Recuperado de http://revistas.umce.cl/index.php/contextos/article/download/312/281

González, F. (2015). Análisis crítico del discurso de los "memes" alusivos al debate sobre paramilitarismo del Congreso de la República de Colombia (2014). Recuperado de http:// hdl.handle.net/10893/11840

Guano, K. (2018). Memess de la cuenta» El tío guayaco» y su construcción de opinión pública en jóvenes de la cooperativa Independencia 1, Guayaquil, 2018 (Bachelorss thesis, Universidad de Guayaquil, Facultad de Comunicación Social). Recuperado de http://repositorio.ug.edu.ec/handle/redug/32729

Knobel, M. \& Lankshear, C. (2007). Online memes, affinities, and cultural production. A new literacies sampler, 29, 199-227. Recuperado de http://literacyandtech.pbworks.com/f/ Text.pdf\#page $=209$

Lull, J. \& Neiva, E. (2011). Hacia una nueva conceptualización evolutiva de la comuni- 
cación «cultural». Comunicar, 18(36), 25-34. Recuperado de https://www.redalyc.org/ pdf/158/15817007004.pdf

Malo, P.; Medrano, J. y Uriarte, J. (2010). Memes y psiquiatría (2). Los memes y la industria y la literatura científica. Biología de los memes y defensas frente a su actuación. Norte de salud mental, vol. VIII, n 36: 35-44. Recuperado de: https://dialnet.unirioja.es/descarga/ articulo/4830426.pdf

Martínez, J. (2018). Una aproximación retórica a los memes de Internet. Signa: Revista de la Asociación Española de Semiótica, (27), 995-1021. Recuperado de https://dialnet.unirioja.es/servlet/articulo?codigo $=6364345$

Martínez, P. (2011). El método de estudio de caso Estrategia metodológica de la investigación científica. Revista cientifica Pensamiento y Gestión, (20). Recuperado de http:// rcientificas.uninorte.edu.co/index.php/pensamiento/article/view/3576/2301

Martínez, S. (2018). Reproducción de pensamiento y cosmovisiones en la web 2.0: el caso del meme en Andalucía. Aportación interdisciplinar a los retos de la comunicación y la cultura en el siglo XXI, 181-204. Recuperado de https://idus.us.es/xmlui/handle/11441/87945

Martínez, X.; \& Piñeiro, T. (2016). The use of memes in the discourse of political parties on Twitter: analysing the 2015 state of the nation debate. Communication \& Society, 29(1), 145-159. Recuperado de https://dadun.unav.edu/bitstream/10171/40180/1/Xabier\%20 Mart\%C3\%ADnez.pdf

Martínez, X.; \& Piñeiro, T. (2017). El uso de los memes en la conversación política 2.0 una aproximación a una movilización efímera. Prisma Social, (18), 55-84. Recuperado de https://www.redalyc.org/pdf/3537/353751820003.pdf

Medina, F. (2018). Los memes como discurso analizable en el aula. Cuaderno de Pedagogía Universitaria, 15(30), 12-21. Recuperado de https://dialnet.unirioja.es/servlet/articulo?codigo $=6855119$

Meso-Ayerdi, K.; Mendiguren-Galdospín, T. \& Pérez-Dasilva, J. (2017). Memes políticos difundidos por usuarios de Twitter. Análisis de la jornada electoral del 26J de 2016. El profesional de la información, 26(4), 672-683. Recuperado de https://www.scipedia.com/ wd/images/b/b3/Draft_Content_545012725-59525-9544-document.pdf

Milner, R. (2012). The world made meme: Discourse and identity in participatory media (Doctoral dissertation, University of Kansas). Recuperado de https://kuscholarworks. ku.edu/bitstream/handle/1808/10256/Milner_ku_0099D_12255_DATA_1.pdf

Milner, R. (2013). Pop polyvocality: Internet memes, public participation, and the Occupy Wall Street movement. International Journal of Communication, 7, 34. Recuperado de http://ijoc.org/index.php/ijoc/article/download/1949/1015

Muñoz, C. (2014). El meme como evolución de los medios de expresión social. Repositorio Académico de la Universidad de Chile. Recuperado de http://repositorio.uchile.cl/bitstream/handle/2250/129749/El\%20meme\%20como\%20evoluci\%F3n\%20de\%20los\%20 medios $\% 20 \mathrm{de} \% 20$ expresi $\% \mathrm{~F} 3 \mathrm{n} \% 20$ social.pdf?sequence $=1$

N/A. (2019). Comunicado del Gobierno de España sobre México. MAEC. Comunicado 062. Recuperado de http://www.exteriores.gob.es/Portal/es/SalaDePrensa/Comunicados/Paginas/2019_COMUNICADOS/20190325_COMU062.aspx

O'halloran, $\overline{\mathrm{K}}$. (2016). Análisis del discurso multimodal. ALED 12(1), 75-97. Recuperado de http://raled.comunidadaled.org/index.php/raled/article/view/78

Pérez, M. (2001). Ironía, humor e inferencia: procesos cognitivos: tendencias creativas en la publicidad actual. Acciones e investigaciones sociales, (12), 129-142. Recuperado de https://papiro.unizar.es/ojs/index.php/ais/article/view/197

Piñeiro, T.; \& Martínez, X. (2016). Los memes en el activismo feminista en la Red: \#Viajo- 
Sola como ejemplo de movilización transnacional. Cuadernos. info, (39), 17-37. Recuperado de https://scielo.conicyt.cl/scielo.php?pid=S0719-367X2016000200002\&script=Sci arttext

Pirandello, L. (2002). Esencia, caracteres y materia del humorismo. CIC. Cuadernos de Información y Comunicación, (7), 95-130. Recuperado de https://www.redalyc.org/ pdf/935/93500707.pdf

Poulshock, J. (2002). The problem and potential of memetics. Journal of Psychology and Theology, 30(1), 68-80. Recuperado de https://www.researchgate.net/profile/Joseph_Poulshock/publication/289804399_The_Problem_and_Potential_of_Memetics/ links/5ac32d7baca27222c75d442e/The-Problem-and-Potential-of-Memetics.pdf

Provoste, M.; Vásquez, J.; Pérez, A.; \& Torres, Y. (2017). La producción de memes como recurso evaluativo de la lectura crítica de textos literarios: un enfoque en la problemática de los estereotipos de género (Doctoral dissertation, Universidad Católica de la Santísima Concepción). http://repositoriodigital.ucsc.cl/bitstream/handle/25022009/1184/ Amaro\%20P\%C3\%A9rez\%20Fierro.pdf?sequence=1\&isAllowed=y

Reyes, T. (1999). Métodos cualitativos de investigación: los grupos focales y el estudio de caso. In Forum empresarial (Vol. 4, No. 1, pp. 74-87). Universidad de Puerto Rico. Recuperado de https://dialnet.unirioja.es/servlet/articulo? codigo $=6230192$

Rolán, X., et Otero, T. (2017). El uso de los memes en la conversación política 2.0 una aproximación a una movilización efímera. Prisma Social, (18), 55-84. Recuperado de https:// www.redalyc.org/pdf/3537/353751820003.pdf

Romero, L. (2015). Memes y Opinión Pública ¿Una Relación Posible? Diálogos de la comunicación, (91), 8. Recuperado de https://dialnet.unirioja.es/servlet/articulo?codi$\mathrm{go}=6845112$

Rowan, J. (2015). Memes: Inteligencia idiota, política rara y folclore digital (Vol. 6). Capitán swing libros. Madrid.

Ruiz, E. (2018). Los memes: una respuesta popular y humorística ante la crisis mexicana. NUSO (273). Recuperado de https://nuso.org/articulo/los-memes-una-respuesta-popular-y-humoristica-ante-la-crisis-mexicana/

Ruiz, J. (2018). Una aproximación retórica a los memes de internet. Signa: Revista de la Asociación Española de Semiótica (27), 995-1021. Recuperado de https://dialnet.unirioja.es/ servlet/articulo?codigo $=6364345$

Sandoval, L. (2017). Semiosis ilimitada, producción de sentido en memes de internet. Jornadas de Investigación de la Facultad de Información y Comunicación 2017. Universidad de la República de Uruguay. Recuperado de http://www.academia.edu/download/56849899/ GT20-Sandoval-SEMIOSIS-ILIMITADA-PRODUCCION-DE-SENTIDO-EN-MEMES.pdf

Segev, E. (2015). Families and networks of internet memes: the relationship between cohesiveness, uniqueness, and quiddity concreteness. Journal of Computer-Mediated Communication (20) 417-433. Recuperado de https://academic.oup.com/jcmc/article/20/4/417/4067574

Shifman, L. (2012). An anatomy of a YouTube meme. New Media \& Society, 14(2), 187-203. Recuperado de https://journals.sagepub.com/doi/pdf/10.1177/1461444811412160

Shifman, L. (2014). Memes in digital culture. MIT Press. EE.UU.

Siri, L. (2016). Memes en internet: el escándalo Snowden. Letra. Imagen. Sonido: Ciudad Mediatizada, (16), 16-39. Recuperado de https://dialnet.unirioja.es/descarga/articu1o/5837694.pdf

Vélez, J. (2012) Los memes de Internet y su papel en los medios de comunicación mexica- 
nos. Memoria: XXIV Encuentro Nacional AMIC. Saltillo, Coahuila. Pp. 113-122 Recuperado de https://www.researchgate.net/publication/318982307_Las_memes_de_Internet_y_su_papel_en_los_medios_de_comunicacion_mexicanos

Vera, E. (2016). El meme como nexo entre el sistema educativo y el nativo digital: tres propuestas para la enseñanza de Lenguaje y Comunicación. Revista educación y tecnología, (9), 1-15. Recuperado de https://dialnet.unirioja.es/descarga/articulo/6148882.pdf

Yin, R. (1994). Case Study Research - Design and Methods, Applied Social Research Methods (Vol. 5, 2nd ed.), Newbury Park, CA, Sage. 